\title{
Exposure to Hookah and Cigarette Smoke in Children and Adolescents According to Their Socio-Economic Status: The CASPIAN-IV Study
}

\author{
Roya Kelishadi, ${ }^{1}$ Armindokht Shahsanai, ${ }^{1}$ Mostafa Qorbani, ${ }^{2,3}$ Gelayol Ardalan, ${ }^{4}$ Parinaz Poursafa, ${ }^{5}$ \\ Ramin Heshmat, ${ }^{3}$ and Mohammad Esmaeil Motlagh ${ }^{4,6, *}$ \\ ${ }^{1}$ Department of Pediatrics, Child Growth and Development Research Center, Research Institute for Primordial Prevention of Non-Communicable Disease, Isfahan University \\ of Medical Sciences, Isfahan, IR Iran \\ ${ }^{2}$ Department of Community Medicine, Alborz University of Medical Sciences, Karaj, IR Iran \\ ${ }^{3}$ Department of Epidemiology, Chronic Diseases Research Center, Endocrinology and Metabolism Population Sciences Institute, Tehran University of Medical Sciences, \\ Tehran, IR Iran \\ ${ }^{4}$ Bureau of Population, Youth and School Health, Ministry of Health and Medical Education, Tehran, IR Iran \\ ${ }^{5}$ Environmental Health Department, Environment Research Center, Research Institute for Primordial Prevention of Non-Communicable Diseases, Isfahan University of \\ Medical Sciences, Isfahan, IR Iran \\ ${ }^{6}$ Department of Pediatrics, Ahvaz Jundishapur University of Medical Sciences, Ahvaz, IR Iran \\ "Corresponding author: Mohammad Esmaeil Motlagh, Department of Pediatrics, Ahvaz Jundishapur University of Medical Sciences, Ahvaz, IR Iran. Tel: +98-9122995592, Fax: \\ +98-2181450007, E-mail: cgdrc@med.mui.ac.ir
}

Received 2015 June 17; Revised 2015 November 23; Accepted 2015 December 16.

\begin{abstract}
Background: Exposure to smoking or passive smoking is one of serious health problems especially in the pediatric age group. Objectives: To compare the prevalence and determinants of passive smoking in a nationally representative sample of Iranian children and adolescents according to their socioeconomic status (SES).

Materials and Methods: This nationwide study was conducted in 2011 - 2012 among 14880 students aged 6 - 18 years, living in 30 provinces in Iran. Exposure to the smoke of hookah or cigarette was documented by using validated questionnaires. Possible influencing factors were determined and the frequency of passive smoking was compared according to the regional and familial SES.

Results: Participants consisted of 13,486 children and adolescents including 49.2\% girls and 75.6\% urban inhabitants (90.6\% participation rate). The mean age of participants was $12.47 \pm 3.36$ years. Overall, $43.87 \%$ of them ( $44.07 \%$ of boys and $43.66 \%$ of girls) were exposed to second hand smoke at home. Exposures to hookah or cigarette smoke at home were respectively reported in $21.46 \%$ and $34.49 \%$ of participants. The prevalence of passive smoking was lower in children of families with higher SES level, but higher in high SES regions of the country than in low SES ones, and ranged from $39.2 \%$ in the region with lowest SES to $49.05 \%$ in the highest SES region. Higher education levels of fathers and mothers were significantly associated with lower frequency of passive smoking. Conclusions: Exposure to second hand smoke is a major problem among Iranian children and adolescents. Low family SES and low parental education increased the frequency of passive smoking. Appropriate public health education and legislation for smoke free home as well as family-centered counseling should be strengthened.
\end{abstract}

Keywords: Passive Smoking, Determinants, Children and Adolescents, Socio-Economic Status

\section{Background}

Exposure to smoking or passive smoking is one of serious health problems especially in the pediatric age group. Second hand smoke has several adverse health effects on different organs, namely respiratory and cardiovascular systems (1-3).

Worldwide burden of disease from exposure to tobacco smoke revealed that $40 \%$ of children were exposed to second hand smoke, which was responsible for $38 \%$ of deaths in this age group. This study also showed that the African region was the lowest exposed area to second hand smoke, followed by the American and the Eastern Mediterranean regions. The highest prevalence of passive smoking was documented in Europe, the Western Pacific, and some countries in Southeast Asia (2).

Findings of the global youth tobacco survey (GYTS, 2007) showed high prevalence of passive smoking among Iranian students aged 13 - 15 years, i.e., 35.4\% at home and $44.8 \%$ in public places (4).

Some studies showed that passive smoking might be related to the parental education and the socioeconomic status (SES) (5-7). Increasing our knowledge about the determinants of exposure to second hand smoke in different populations would help in implementing preventive programs. 


\section{Objectives}

The aim of the present study is to compare the prevalence of passive smoking in a nationally representative sample of Iranian children and adolescents at national and subnational levels with different patterns of SES.

\section{Materials and Methods}

The data of this study were collected as a part of the "national survey of school student high risk behaviors" (2011 - 2012), as the fourth survey of the school-based surveillance system entitled childhood and adolescence surveillance and prevention of adult non-communicable disease (CASPIAN-IV) study. This school-based nationwide health survey was conducted in 30 provinces in Iran. Details on the study protocol have been defined before (8), and here we report it in brief.

\subsection{Study Population and Sampling Framework}

The study population consisted of 14,880 school students, aged 6 - 18 years. Those with Iranian nationality (Iranian identification: identity card), without any underlying disease and medication use were included; those without compliance in completing the study were excluded. They were selected by multistage, cluster sampling method from urban and rural areas of different cities in 30 provinces of the country (48 clusters of 10 students in each province). Stratification was executed in each province according to the residence area (urban/rural) and school grade (elementary/intermediate/high school). The sampling was proportional to size with equal sex ratio; i.e., selections of boys and girls from each province were equal numbers and the ratios in urban and rural areas were balanced to the population of urban and rural students. In this way, the number of samples in rural/urban areas and in each school grade was divided equivalently to the population of students in each grade. Cluster sampling with equal clusters was used in each province to scope the required sample size. Clusters concluded the level of schools, including 10 sample units (students and their parents) in each cluster. The maximum sample size that could give a good estimate of all risk factors of interest was selected. Thus, the sample size was calculated as 480 students in each province. A total of 48 clusters of 10 subjects in each of the provinces and a total of 14,880 students were selected.

For comparing the findings in various parts of the country with different SES levels, the country was classified into four sub-national regions as determined in a previous study. The sub-national regions were categorized based on criteria of the combination of geography and SES using principal component analysis (PCA). SES was an index consisting of variables from the 2006 census, including literacy, family income and occupation. According to this classification, the lowest to highest SES are considered for Southeast, North-Northeast, West, and the Central regions, respectively (9). Family SES level was determined using principal component analysis (PCA) method taking into account parental education, parents' job, possessing private car, school type (public/private), and having personal computer in home,

\subsection{Questionnaires}

The questionnaire of students was prepared in Persian based on the questionnaire of the world health organization-global school-based student health survey (WHO-GSHS), and some questions were added; moreover a questionnaire was prepared for the parents. The validity and reliability of these questionnaires were confirmed (10). The students were reassured about the confidentiality of their answers; the questionnaires were completed anonymously.

Questions were about demographic characteristics, parents' education level, patterns of passive smoking, students' educational level, birth order, number of children in family, family size, smoker in household members, parents' job, possessing private car, school type (public/private), and having personal computer. Those students who reported to have a household member to smoke hookah or cigarette were considered as passive smoker.

\subsection{Ethical Concerns}

The study procedures were reviewed and approved by national regulatory organizations and the ethics committee of Isfahan University of Medical sciences. After explaining the study aims and protocols, written consent and verbal assent were obtained from parents and students, respectively.

\subsection{Statistical Analysis}

Continuous variables are reported as mean (95\% confidence interval, $\mathrm{CI}$ and categorical variables as percentage, $95 \% \mathrm{CI}$ ). Variables across regions were compared by trend analysis. Chi-square test was used to compare the prevalence rates in different areas and age groups.

Statistical measures were assessed using survey data analysis methods in the STATA Corp. 2011, STATA Statistical Software (Release 12. College Station, TX: STATA Corp LP. Package). P value $<0.05$ was considered as statistically significant. 


\section{Results}

The population of this survey consisted of 13,486 children and adolescents (participation rate of 90.6\%) including $49.2 \%$ girls and $75.6 \%$ urban inhabitants. The mean age of participants was $12.47 \pm 3.36$ years, without significant difference between boys (12.36 \pm 3.40 years) and girls (12.58 \pm 3.32 years).

According to the self-report of students, $43.87 \%$ of them ( $44.07 \%$ of boys and $43.66 \%$ of girls) were exposed to secondhand smoke at home. Table 1 presents the demographic characteristics of the participants; it shows that the prevalence of passive smoking was significantly different neither between boys and girls, nor between rural and urban inhabitants.

The prevalence of passive smoking was significantly higher in high school students (47.09\%, 95\% CI: 44.86 49.32 ) than in students at middle school (43.89\%, 95\% CI: 41.6 - 46.21) and elementary school (41.88\%, 95\% CI: 40.15, 43.63) levels $(\mathrm{P}=0.001)$.

The prevalence of passive smoking was lower in children of families with high SES level (39.28\%; 95\% CI: 37.4541.13) compared to those with middle (46.01\%; 95\% CI: 44.3 47.73) and low (47.45; 95\% CI: 45.54 - 49.38) SES ( $>0.001)$.

Family size and number of children had no significant effect on the prevalence of passive smoking, but it increased with higher birth rank.

Table 2 shows the prevalence of passive smoking by gender, age group, living area, and exposure to hookah or cigarette smoke according to sub-national classification. Exposures to hookah or cigarette smoke at home were respectively reported in $21.46 \%$ and $34.49 \%$ of participants.

The prevalence of passive smoking was significantly higher in high SES regions than in low SES ones. The students living in the Southeast region, i.e., with the lowest SES, had the lowest reported (39.2\%) prevalence of passive smoking in comparison with their counterparts living in the Central region (49.05\%), with highest SES.

As presented in Table 3, higher education levels of fathers and mothers were significantly associated with lower frequency of passive smoking in both boys and girls $(\mathrm{P}<$ 0.001).

Among the students who were exposed to cigarette and hookah smoke, $54.46 \%$ of fathers, $1.14 \%$ of mothers, $3.42 \%$ of siblings, and $29.7 \%$ of other family members were tobacco users.

\section{Discussion}

This study, which is one of the few nationwide studies conducted in the Middle East and North Africa (MENA) region, showed the considerably high prevalence of $43.8 \%$ of passive smoking in Iranian children and adolescents in their homes. Our findings are consistent with some previous studies that had reported prevalence rates as high as $51.1 \%$ (11) and $35.4 \%$ (4) of passive smoking among Iranian students aged 11 - 18 years and 13 - 15 years, respectively. Our results are almost close to the results of these studies, but slight differences can be because of the small sample size and limited geographical distribution of the population studied in previous surveys. However, the prevalence of exposure to second hand smoke was lower in the current study than in the first nationwide survey of the CASPIAN study conducted in 2003 - 2004 (11). This decrease can be because of the higher public awareness during last decade about the adverse health effects of exposure to tobacco smoke.

Many previous studies have evaluated the prevalence of passive smoking in the pediatric age group of different countries. A study in preschool-aged German children showed that $32 \%$ of children were exposed to tobacco smoke at home (12). A study in Turkey reported that 74.3\% of high school students were exposed to second hand smoke (13). A study among high school adolescents in Korea reported that $39.4 \%$ of boys and $40.9 \%$ of girls were exposed to tobacco smoke at home (14).

Data from youth smoking survey (YSS) in 2006 showed that $22.1 \%$ of Canadian high school students were exposed to smoking at home (15). A study in the United States showed that 47 percent of middle school students and 47 percent of high school students were exposed to second hand smoke at home (3).

In the current study, the prevalence of passive smoking at home was higher in participants living in regions with high SES than in those living in low SES regions. Previous studies have reported conflicting results about the prevalence of passive smoking according to SES. Our findings are in line with a study in adult population that showed Italian women with low education had a lower risk of exposure to secondhand smoke than those with higher education level (16).

However, our findings are not consistent with some previous studies conducted in different countries that have shown higher prevalence of passive smoking in low SES (17), low education $(12,18-20)$ and low income $(12,18$, $21,22)$ areas. Such discrepancies can be because of sociocultural differences in various populations, and warrant conducting multi-centric studies with uniform methodology to provide comparable data in different populations and/or large variations in the definition of SES and its categories.

In the current study, higher parental education was significantly associated with lower frequency of passive smoking in both boys and girls. This finding is consistent 
Table 1. Demographic Characteristics of Children and Adolescents with and Without Passive Smoking: The CASPIAN-IV Study

\begin{tabular}{|c|c|c|c|}
\hline \multirow[t]{2}{*}{ Variables } & \multicolumn{3}{|c|}{ Passive Smoking } \\
\hline & Yes, \%, (95\%CI) & No, $\%,(95 \% C I)$ & P Value \\
\hline Gender & & & 0.72 \\
\hline Boy & $44.07,(42,43,45,73)$ & $55.93,(54,27,57,57)$ & \\
\hline Girl & $43.66,(42,06,45,27)$ & $56,34,(54,73,57,94)$ & \\
\hline Living area & & & 0.99 \\
\hline Urban & $43,87,(42,58,45,17)$ & $56,13,(34,83,57,42)$ & \\
\hline Rural & $43,87,(41,32,46,46)$ & $56,13,(53,54,58,68)$ & \\
\hline Student educational level & & & 0.001 \\
\hline Elementary & $41,88,(40,15,43,63)$ & $58,12,(56,37,59,85)$ & \\
\hline Middle & $43,89,(41,6,56,21)$ & $56,11,(53,79,58,4)$ & \\
\hline High & $47,09,(44,86,49,32)$ & $52,91,(50,68,55,14)$ & \\
\hline Total & $43,87,(42,74,45)$ & $56,13,(55,57,26)$ & \\
\hline Birth rank & & & 0.03 \\
\hline 1 & $43,36,(41,82,44,91)$ & $56,64,(55,09,58,18)$ & \\
\hline 2 & $42,62,(40,8,44,47)$ & $57,38,(55,53,59,2)$ & \\
\hline 3 & $45,87,(43,49,48,27)$ & $54,13,(51,73,56,51)$ & \\
\hline$\geq 4$ & $45,97,(43,53,48,43)$ & $54,03,(51,57,56,47)$ & \\
\hline Number of children & & & 0.244 \\
\hline$<2$ & $43,16,(41,64,44,69)$ & $56,84,(55,31,58,36)$ & \\
\hline $2-4$ & $44,19,(42,65,45,74)$ & $55,81,(54,26,57,35)$ & \\
\hline$>4$ & $45,42,(42,8,48,07)$ & $54,58,(51,93,57,2)$ & \\
\hline Family household number & & & 0.90 \\
\hline$\leq 4$ & $43,09,(42,52,45,46)$ & $56,01,(54,54,57,48)$ & \\
\hline$>4$ & $43,87,(42,41,45,34)$ & $56,13,(54,66,56,59)$ & \\
\hline Family socioeconomic status & & & $<0.001$ \\
\hline Low & $47,45,(45,54,49,38)$ & $52,55,(50,62,54,48)$ & \\
\hline Middle & $46,01,(44,3,47,73)$ & $53,99,(52,27,55,7)$ & \\
\hline Good & $39,28,(37,45,41,13)$ & $60,72,(58,87,62,55)$ & \\
\hline
\end{tabular}

with some previous studies in other countries. A study in China reported that 68 percent of children with less than 18 years of age were exposed to second hand smoke at home, with higher frequency in low-educated and lowincome families than in those with higher education and income (23). This finding is in line with a study in Korea (17), and a study in Finland that showed reduction in frequency of passive smoking among children whose father had low education level was lower than children whose father had high education level (24).

In the current survey, exposure to tobacco smoke was less frequent in higher family SES than in lower family SES. On the other hand passive smoking was more prevalent in high SES region compared to other regions. This paradox of the association of passive smoking with family and living area SES can be justified by familial and sociocultural nature of smoking. This paradox might exist in different populations, for instance our findings are consistent with the Minnesota adolescent community cohort study that showed low family SES, and high community-level SES increased the risk of smoking in adolescents (25). These findings suggest that the risk of smoking (and in turn passive smoking) is higher in families with low SES even in those living in regions with high SES.

Our finding about the association of low family SES with increased risk of passive smoking is also in line with 


\begin{tabular}{|c|c|c|c|c|c|c|c|c|c|c|}
\hline \multirow{3}{*}{\multicolumn{2}{|c|}{ Variables }} & \multicolumn{3}{|c|}{ Exposure to Tobacco Smoke } & \multicolumn{3}{|c|}{ Exposure to Hookah Smoke } & \multicolumn{3}{|c|}{ Exposure to Cigarette Smoke } \\
\hline & & Boys & Girls & Total & Boys & Girls & Total & Boys & Girls & Total \\
\hline & & $\%,(95 \% \mathrm{CI})$ & $\%,(95 \% \mathrm{CI})$ & $\%,(95 \% \mathrm{CI})$ & $\%,(95 \% \mathrm{CI})$ & $\%,(95 \% \mathrm{CI})$ & $\%,(95 \% \mathrm{CI})$ & $\%,(95 \% \mathrm{CI})$ & $\%,(95 \% \mathrm{CI})$ & $\%,(95 \% \mathrm{CI})$ \\
\hline \multicolumn{11}{|c|}{$\begin{array}{l}\text { Father } \\
\text { education }\end{array}$} \\
\hline & $\begin{array}{l}\text { Illiter- } \\
\text { ate }\end{array}$ & $\begin{array}{c}46.56 \\
(42.38,50.79)\end{array}$ & $\begin{array}{c}\text { 45.68, } \\
(41.28,50.15)\end{array}$ & $\begin{array}{c}46.14 \\
(43.03,49.29)\end{array}$ & $23.33,(.2,2703)$ & $23.62,(.1979, .2792)$ & $\begin{array}{c}23.46 \\
(.2088,2626)\end{array}$ & $36.13,(32.16,40.31)$ & $33.58,(29.68,37.71)$ & $\begin{array}{c}34.92, \\
(32.06,37.89)\end{array}$ \\
\hline & $\begin{array}{l}\text { High } \\
\text { school } \\
\text { diploma } \\
\text { and } \\
\text { under }\end{array}$ & $\begin{array}{c}45.85 \\
(44.06,47.64)\end{array}$ & $\begin{array}{c}46.78 \\
(45.05,48.51)\end{array}$ & $\begin{array}{c}46.31 \\
(45.09,47.53)\end{array}$ & $21.65,(20.21,23.17)$ & $\begin{array}{c}22.48 \\
(21.03,23.99)\end{array}$ & $22.06,(21.05,23.1)$ & $\begin{array}{c}37.34 \\
(35.69,39.02)\end{array}$ & $\begin{array}{c}36.85 \\
(35.22,38.52)\end{array}$ & $37.1,(35.96,38.25)$ \\
\hline & $\begin{array}{l}\text { Univer- } \\
\text { sity }\end{array}$ & $\begin{array}{c}32.89 \\
(29.32,36.68)\end{array}$ & $27.43,(24.4,30.68)$ & $\begin{array}{c}30.19 \\
(27.82,32.68)\end{array}$ & $17.47,(14.92,20.35)$ & $14.41,(12.14,17.03)$ & $15.96,(14.22,17.87)$ & $25.41,(22.31,28.79)$ & $20.13,(17.46,23.1)$ & $22.8,(20.71,25.04)$ \\
\hline & PValue & $<0.001$ & $<0.001$ & $<0.001$ & 0.016 & $<0.001$ & $<0.001$ & $<0.001$ & $<0.001$ & $<0.001$ \\
\hline \multicolumn{11}{|c|}{$\begin{array}{l}\text { Mother } \\
\text { education }\end{array}$} \\
\hline & literate & $44.6,(41.32,47.92)$ & $45.91,(42.27,49.6)$ & $45.22,(42.75,47.71)$ & $22.23,(19.6,25.11)$ & $\begin{array}{c}23.21 \\
(20.26,26.44)\end{array}$ & $.2269,(20.7,24.83)$ & $\begin{array}{c}34.48 \\
(31.44,37.65)\end{array}$ & $34.25,(30.9,37.77)$ & $34.37,(32.11,36.71)$ \\
\hline & $\begin{array}{l}\text { High } \\
\text { school } \\
\text { diploma } \\
\text { and } \\
\text { under }\end{array}$ & $\begin{array}{c}44.96 \\
(43.14,4679)\end{array}$ & $\begin{array}{c}44.69 \\
(42.94,46.46)\end{array}$ & $\begin{array}{c}44.83 \\
(43.59,46.07)\end{array}$ & $21.64,(20.22,23.13)$ & $21.91,(20.45,23.45)$ & $21.78,(20.77,22.82)$ & $36.45,(34.79,38.15)$ & $\begin{array}{c}34.82, \\
(33.23,36.45)\end{array}$ & $\begin{array}{c}35.64, \\
(34.51,36.79)\end{array}$ \\
\hline & $\begin{array}{l}\text { Univer- } \\
\text { sity }\end{array}$ & $35.33,(31.14,39.76)$ & $\begin{array}{c}30.89 \\
(27.05,35.01)\end{array}$ & $33.16,(30.3,36.15)$ & $\begin{array}{c}17.49 \\
(14.49,20.95)\end{array}$ & $15.15,(12.28,18.56)$ & $16.35,(14.23,18.71)$ & $27.02,(23.21,31.2)$ & $23.13,(19.71,26.94)$ & $25.11,(22.51,27.91)$ \\
\hline & PValue & $<0.001$ & $<0.001$ & $<0.001$ & 0.07 & 0.001 & $<0.001$ & $<0.001$ & $<0.001$ & $<0.001$ \\
\hline
\end{tabular}

some previous studies in Australia (26, 27), China (28) and Scotland (29), which had shown that the children of low SES families were at increased risk of exposure to second hand tobacco smoke.

Controversial results exist about the association of family size with passive smoking. A study in Germany showed that small family size was positively associated with exposure to tobacco smoke (12), however a study in Australia found that larger household size increased the risk of passive smoking in children (27). We did not find any significant association between family size and exposure to second hand smoke exposure.

In the current study, the exposure to second hand smoke was significantly more frequent among high school students than in middle and elementary school students. Although this might be attributed to age increment, however to reduce this effect, we had asked about the current status of passive smoking, not its lifelong status. The lower frequency of passive smoking in younger age group, might show that families are more concerned about the adverse health effects of exposure to tobacco smoke in children than in adolescents, and therefore they smoked less in the presence of children. Our finding is in line with a study in the US, in which children had the lowest rates (3.4\%) of exposure to second hand smoke than adolescents (4.7\%) and adults (6.0\%) (30). Likewise, a study conducted in Spain found that the prevalence of exposure to tobacco smoke was greater among participants older than 13 years than in their younger counterparts (31).
In the current study, most children exposed to second hand tobacco smoke were at the exposure of tobacco use by their fathers. This finding is in line with some previous studies in different populations (11-13,32). In addition to increasing the knowledge, it is necessary to change the attitude and practice of parents, notably fathers, about smoking and its adverse health effects for their children.

Iran signed the WHO framework convention on tobacco control in 2003, and ratified it in November 2005; different articles of this treaty are being considered at public level, however the high prevalence of exposure of children and adolescents to tobacco smoke in their homes shows that family-centered counseling against tobacco use should be intensified in Iran.

\subsection{Study Limitations and Strengths}

The main limitation of the current study is its crosssectional nature and its questionnaire-based design, and not examining biochemical factors, as surrogate marker of passive smoking. Moreover, this study could determine the exposure of participants to second hand smoking only at home, and could not assess their exposure in other places as cars, public places, visiting other families and friends. The strengths of this study were its large sample size, the balanced distribution of samples at national and subnational levels, and using a valid questionnaire, as well as consideration of SES and comparison of the findings at subnational level. 


\subsection{Conclusion}

Exposure to second hand smoke is a major problem among Iranian children and adolescents. Low family SES and low parental education influenced the frequency of passive smoking. Our findings provide evidence for public health policy makers in developing action-oriented intervention strategies to efficiently tackle this health and social issue, and to highlight the participation of families in health promoting activities. In addition to the current public interventions for tobacco control, appropriate family education and legislation for smoke free home and family-centered counseling against tobacco use should be strengthened.

\section{Acknowledgments}

This study was conducted as part of a national schoolbased surveillance program. The authors would like to forward sincere thanks to the large team working with this project in different cities.

\section{References}

1. US Department of Health and Human Services. A Report of the Surgeon General: How Tobacco Smoke Causes Disease. Atlanta: Centers for Disease Control and Prevention; 2010.

2. Oberg M, Jaakkola MS, Woodward A, Peruga A, Pruss-Ustun A Worldwide burden of disease from exposure to second-hand smoke: a retrospective analysis of data from 192 countries. Lancet. 2011;377(9760):139-46. doi: 10.1016/S0140-6736(10)61388-8. [PubMed: 21112082].

3. US Department of Health and Human Services. The Health Consequences of Involuntary Exposure to Tobacco Smoke: A Report of the Surgeon General. Atlanta: Centers for Disease Control and Prevention; 2006.

4. Centers for Disease Control and Prevention, Atlanta, USA, Global Tobacco Surveillance System Data, Eastern Meditranian region, Iran, National 2007. Available from: http://nccd.cdc.gov/GTSSData/ Ancillary/Location.aspx.

5. Mazloomzadeh S, Abrishami BS, Moezzi F. P1-470 Socioeconomic determinants of passive smoking during pregnancy and birth weight of newborns. J Epidemiol Community Health. 2011;65(Suppl 1):197.

6. Pisinger C, Hammer-Helmich L, Andreasen AH, Jorgensen T, Glumer C. Social disparities in children's exposure to second hand smoke at home: a repeated cross-sectional survey. Environ Health. 2012;11:65. doi: 10.1186/1476-069X-11-65. [PubMed: 22984822].

7. Moore GF, Holliday JC, Moore LA. Socioeconomic patterning in changes in child exposure to secondhand smoke after implementation of smoke-free legislation in Wales. Nicotine Tob Res. 2011;13(10):903-10. doi: 10.1093/ntr/ntr093. [PubMed: 21571691]

8. Kelishadi R, Ardalan G, Qorbani M, Ataie-Jafari A, Bahreynian M, Taslimi M, et al. Methodology and Early Findings of the Fourth Survey of Childhood and Adolescence Surveillance and Prevention of Adult Non-Communicable Disease in Iran: The CASPIAN-IV Study. Int J Prev Med. 2013;4(12):1451-60. [PubMed: 24498502]

9. Farzadfar F, Danaei G, Namdaritabar H, Rajaratnam JK, Marcus JR, Khosravi A, et al. National and subnational mortality effects of metabolic risk factors and smoking in Iran: a comparative risk assessment. Popul Health Metr. 2011;9(1):55. doi: 10.1186/1478-7954-9-55. [PubMed: 21989074].
10. Kelishadi R, Majdzadeh R, Motlagh ME, Heshmat R, Aminaee T, Ardalan G, et al. Development and Evaluation of a Questionnaire for Assessment of Determinants of Weight Disorders among Children and Adolescents: The Caspian-IV Study. Int J Prev Med. 2012;3(10):699705. [PubMed: 23112896].

11. Kelishadi R, Ardalan G, Gheiratmand R, Majdzadeh R, Delavari A, Heshmat R, et al. Smoking behavior and its influencing factors in a national-representative sample of Iranian adolescents: CASPIAN study. Prev Med. 2006;42(6):423-6. doi: 10.1016/j.ypmed.2006.03.001. [PubMed: 16624397].

12. Bolte G, Fromme H, GME Study Group . Socioeconomic determinants of children's environmental tobacco smoke exposure and family's home smoking policy. Eur J Public Health. 2009;19(1):52-8. doi: 10.1093/eurpub/ckn114. [PubMed: 19033356].

13. Ozge C, Toros F, Bayramkaya E, Camdeviren H, Sasmaz T. Which sociodemographic factors are important on smoking behaviour of high school students? The contribution of classification and regression tree methodology in a broad epidemiological survey. Postgrad Med J. 2006;82(970):532-41. doi:10.1136/pgmj.2005.040360. [PubMed: 16891446].

14. Lee HR, Kim HK, Yoo JS, Kim KN, Lee SY, Yoo SM, et al. Urine Cotinine and Environmental Tobacco Exposure in Korean Adolescents. Korean JFam Med. 2009;30(1):31-8.

15. Leatherdale ST,Ahmed R. Second-hand smoke exposure in homes and in cars among Canadian youth: current prevalence, beliefs about exposure, and changes between 2004 and 2006. Cancer Causes Control. 2009;20(6):855-65. doi: 10.1007/s10552-009-9306-2. [PubMed: 19219635].

16. Simoni M, Baldacci S, Puntoni R, Pistelli F, Farchi S, Lo Presti E, et al. Plasma, salivary and urinary cotinine in non-smoker Italian women exposed and unexposed to environmental tobacco smoking (SEASD study). Clin Chem Lab Med. 2006;44(5):632-8. doi: 10.1515/CCLM.2006.098. [PubMed: 16681437].

17. Yi O, Kwon HJ, Kim D, Kim H, Ha M, Hong SJ, et al. Association between environmental tobacco smoke exposure of children and parental socioeconomic status: a cross-sectional study in Korea. Nicotine Tob Res. 2012;14(5):607-15. doi: 10.1093/ntr/ntr259. [PubMed: 22193578].

18. Harris JK, Geremakis C, Moreland-Russell S, Carothers BJ, Kariuki B, Shelton SC, et al. Demographic and geographic differences in exposure to secondhand smoke in Missouri workplaces, 2007-2008. Prev Chronic Dis. 2011;8(6):A135. [PubMed: 22005628].

19. Scarinci IC, Watson JM, Slawson DL, Klesges RC, Murray DM, EckClemens LH. Socioeconomic status, ethnicity, and environmental tobacco exposure among non-smoking females. Nicotine Tob Res. 2000;2(4):355-61. [PubMed: 11197316].

20. Wang CP, Ma SJ, Xu XF, Wang JF, Mei CZ, Yang GH. The prevalence of household second-hand smoke exposure and its correlated factors in six counties of China. Tob Control. 2009;18(2):121-6. doi: 10.1136/tc.2008.024836. [PubMed: 19131456].

21. Kit BK, Simon AE, Brody DJ, Akinbami LJ. US prevalence and trends in tobacco smoke exposure among children and adolescents with asthma. Pediatrics. 2013;131(3):407-14. doi: 10.1542/peds.2012-2328. [PubMed: 23400612].

22. Cai L, Wu X, Goyal A, Han Y, Cui W, He J, et al. Multilevel analysis of the determinants of smoking and second-hand smoke exposure in a tobacco-cultivating rural area of southwest China. Tob Control. 2013;22 Suppl 2:ii16-20. [PubMed: 23708268].

23. Yao T, Sung HY, Mao Z, Hu TW, Max W. Secondhand smoke exposure at home in rural China. Cancer Causes Control. 2012;23 Suppl 1:109-15. doi: 10.1007/s10552-012-9900-6. [PubMed: 22327886].

24. Raisamo SU, Doku DT, Heloma A, Rimpela AH. Persistence of socioeconomic differences in adolescents' environmental tobacco smoke exposure in Finland: 1991-2009. Scand J Public Health. 2014;42(2):184-93. doi: 10.1177/1403494813514301. [PubMed: 24327673] 
25. Mathur C. Socioeconomic status and tobacco use behavior in adolescence. Minnesota: University Of Minnesota; 2010.

26. Bonevski B, Paul C, Jones A, Bisquera A, Regan T. Smoky homes: gender, socioeconomic and housing disparities in second hand tobacco smoke (SHS) exposure in a large population-based Australian cohort Prev Med. 2014;60:95-101. doi: 10.1016/j.ypmed.2013.12.024. [PubMed: 24380792].

27. Longman JM, Passey ME. Children, smoking households and exposure to second-hand smoke in the home in rural Australia: analysis of a national cross-sectional survey. BMJ Open. 2013;3(7) doi: 10.1136/bmjopen-2013-003128. [PubMed: 23833145].

28. Zhang DM, Hu Z, Orton S, Wang JJ, Zheng JZ, Qin X, et al. Socioeconomic and psychosocial determinants of smoking and passive smoking in older adults. Biomed Environ Sci. 2013;26(6):453-67. doi: 10.3967/0895-3988.2013.06.006. [PubMed: 23816579].

29. Akhtar PC, Haw SJ, Levin KA, Currie DB, Zachary R, Currie CE. So- cioeconomic differences in second-hand smoke exposure among children in Scotland after introduction of the smoke-free legislation. J Epidemiol Community Health. 2010;64(4):341-6. doi: 10.1136/jech.2008.084178. [PubMed: 19679709].

30. Max W, Sung HY, Shi Y. Exposure to secondhand smoke at home and at work in California. Public Health Rep. 2012;127(1):81-8. [PubMed: 22298925].

31. Jimenez-Ruiz CA, Miranda JA, Hurt RD, Pinedo AR, Reina SS, Valero FC. Study of the impact of laws regulating tobacco consumption on the prevalence of passive smoking in Spain. Eur J Public Health. 2008;18(6):622-5. doi: 10.1093/eurpub/ckn066. [PubMed: 18676987].

32. Arghir OC, Dantes E, Stoicescu R, Baicu I, Halichidis S, Ciobotaru $\mathrm{C}$, et al. Parental environmental tobacco smoking and the prevalence of respiratory diseases in primary school children. Pneumologia. 2013;62(3):178-81. [PubMed: 24274004]. 
Table 2. Comparison of the Frequency of Passive Smoking in Children and adolescents at National and Sub-National Level: The CASPIAN-IV Study

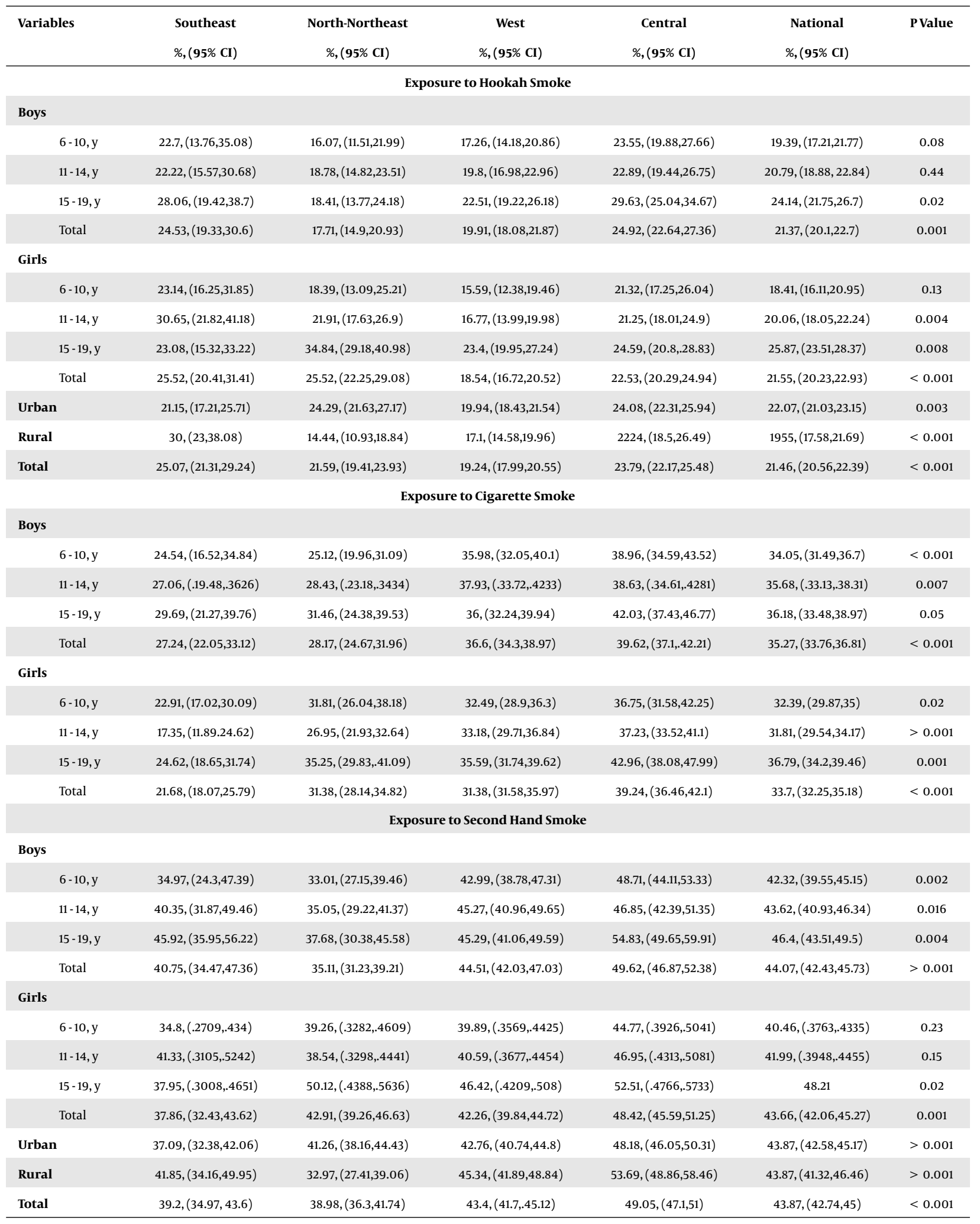

